\title{
Delayed response in a plant-pollinator system to experimental grassland fragmentation
}

\author{
Hans-Peter Rusterholz • Bruno Baur
}

Received: 16 June 2009 / Accepted: 13 January 2010 / Published online: 13 February 2010

(C) Springer-Verlag 2010

\begin{abstract}
The fragmentation of natural habitat is considered to be a major threat to biodiversity. Decreasing habitat quality and quantity caused by fragmentation may lead to a disruption of plant-pollinator interactions and to a reduction in sexual reproduction in plant species. We conducted a 6-year field experiment to investigate the effects of smallscale fragmentation on plant-pollinator interactions and genetic diversity in the self-compatible Betonica officinalis. We examined the abundance and composition of pollinators, the foraging behaviour of bumblebees and the performance, outcrossing rate and genetic diversity of B. officinalis after 2 and 6 years in experimentally fragmented nutrient-poor, calcareous grassland in the northern Swiss Jura mountains. Fragments of different size (2.25 and $20.25 \mathrm{~m}^{2}$ ) were isolated by a 5-m-wide strip of frequently mown vegetation. Control plots of corresponding size were situated in adjacent undisturbed grassland. Experimental grassland fragmentation altered the composition of B. officinalis pollinators and reduced their flower visitation rate. Furthermore, the foraging behaviour of bumblebees was changed in the fragments. After 6 years of fragmentation seed weight was higher in fragments than in control plots. However, the densities of B. officinalis rosettes and inflorescences, plant height and inflorescence length were
\end{abstract}

Communicated by Rebecca Irwin.

Electronic supplementary material The online version of this article (doi:10.1007/s00442-010-1567-7) contains supplementary material, which is available to authorized users.

H.-P. Rusterholz $(\bowtie) \cdot$ B. Baur

Section of Conservation Biology,

Department of Environmental Sciences,

University of Basel, St. Johanns-Vorstadt 10,

4056 Basel, Switzerland

e-mail: hans-peter.rusterholz@unibas.ch not affected by fragmentation. The outcrossing frequency of B. officinalis growing in fragments was reduced by $15 \%$ after 2 years and by $33 \%$ after 6 years of experimental fragmentation. This resulted in a significant reduction of the genetic diversity in seedlings emerging in fragments after 6 years. Our study shows that small-scale habitat fragmentation can disturb the interaction between B. officinalis and pollinators resulting in a reduced outcrossing frequency and genetic diversity in plants growing in fragments. However, the response to fragmentation was considerably delayed. This finding strengthens the claim for long-term field experiments with proper replications and controls to assess delayed effects of habitat fragmentation.

Keywords Betonica officinalis - Genetic diversity · Pollinator foraging behaviour - Outcrossing frequency . Self-compatibility

\section{Introduction}

The fragmentation of natural habitats is generally considered to be a major threat to biodiversity (Saunders et al. 1991). Fragmentation reduces the area suitable for organisms and leads to isolation and decreased size of remnant populations in plants and animals (Gilpin and Soulé 1986). The disadvantages suffered by small populations involve greater sensitivity to environmental and demographic stochasticity (Holsinger 2000), which together with a loss of genetic diversity and inbreeding depression result in a high risk of local extinction (Krauss et al. 2004). Furthermore, effects of habitat fragmentation may lead to the disruption of biotic interactions such as parasitism, seed dispersal or pollination and hence, can affect species with previously stable populations (Kearns et al. 1998; Groppe et al. 2001). 
Pollinators are of crucial importance for ecosystem services (Klein et al. 2007). Worldwide approximately $80 \%$ of the flowering plant species depend on animals for their pollination (Buchmann and Nabhan 1996). Habitat fragmentation may affect the behaviour, abundance and community composition of pollinators (Aizen and Feinsinger 1994; Goverde et al. 2002). Alterations in behaviour, frequency and composition of flower visitors in turn might influence pollination efficiency which determines the quantity and/or quality of pollen deposited on the stigmas and therefore seed and fruit production (Aizen and Feinsinger 1994; Aguilar and Galetto 2004). Furthermore, habitat fragmentation may alter the spatial distribution of plants causing changes in foraging patterns of flower visitors (Ghazoul 2005). Increased distances between single plants to be pollinated could lead to pollination limitation (Waites and Ågren 2004). Studies addressing fragment size and isolation effects revealed that larger plant populations are more attractive for pollinators, which results in a higher pollination success (e.g. Jennersten 1988; Ågren 1996).

Isolated patches may lead to disruption of plant-pollinator interactions (e.g. Duncan et al. 2004; Ward and Johnson 2005). Pollinator limitation may not occur when the pollinators are able to fly long distances. However, after having moved a long distance, pollinators may stay in an isolated patch for a longer period and thereby repeatedly visit the same flowers (Goverde et al. 2002). The altered pollinator behaviour may increase inbreeding and/or geitonogamy in the plant population resulting in seeds of reduced quality (Lienert 2004).

Plant responses to habitat fragmentation are species specific and related to the degree of pollinator dependency for successful sexual reproduction (Murcia 1996). Theoretical models show that the plant breeding system and degree of pollinator specialization are key traits characterizing the susceptibility to habitat fragmentation (Waser et al. 1996). Self-incompatible plants with specialized pollination systems are highly dependent on pollinator mutualism (Bond 1994), and thus extremely vulnerable to changes in habitat quality and quantity caused by habitat fragmentation because any decrease in pollinator frequency may result in reproductive failure (Aizen et al. 2002). In contrast, self-compatible plants with a generalist pollination system are expected to be more resilient to fragmentationrelated changes in their pollinator communities, because the absence of some pollinators can be buffered by the presence of others (Morris 2003). However, empirical evidence indicates that no generalization can be made concerning the susceptibility to habitat fragmentation of a particular plant species based either on the breeding system or on the specialization of pollinators (Ghazoul 2005; Aguilar et al. 2006).
A variety of plants rapidly respond to changes in habitat quality and connectivity (Lienert 2004). In many cases, however, there is a time lag in the response to the altered habitat (Helm et al. 2006). The magnitude of this time lag depends on the life history, reproductive mode and dispersal ability of the species involved (Ewers and Didham 2006). Perennial plant species with clonal propagation, short-distance dispersal and permanent seed banks exhibit a pronounced time lag in their response to habitat fragmentation (Pacha and Petit 2008). Similarly, plant-pollinator interactions may show a delayed response to habitat fragmentation due to different increases or decreases in the abundance of different pollinators and flower numbers in the varying environmental conditions of the succeeding years. Subtle effects on plant performance and outcrossing frequency and the resulting changes in the genetic diversity of the populations could therefore be overlooked by chance. Long-term field experiments with proper replications and controls are therefore essential to examine effects of habitat fragmentation on pollinator-plant interactions.

In this paper, we report results from a 6-year habitat fragmentation experiment in natural mesocosms (Shrivastava et al. 2004) with a treatment versus control design to examine changes in the interaction between the plant Betonica officinalis and its associated pollinators. In particular, we compare the performance of $B$. officinalis, its flower visitation rate and the species composition of pollinators in fragments and corresponding control plots 2 and 6 years after the initiation of the experimental fragmentation. Using random amplified polymorphic DNA polymerase chain reaction (RAPD-PCR) technique, we also assess the outcrossing rate in $B$. officinalis and the genetic diversity of the seedlings in fragments and control plots 2 and 6 years after the beginning of the experiment. Our sampling design allows an assessment of the time lag in fragmentationrelated changes in the genetic diversity of the plants. As fragmentation may alter the pollinator-plant interaction, we expect both a decrease in outcrossing rate and in genetic diversity of $B$. officinalis 6 years after experimental fragmentation.

\section{Materials and methods}

\section{Study species}

Betonica officinalis (Lamiaceae) is a perennial, selfcompatible herb. It is distributed in Europe from Norway and Sweden to Spain and Bulgaria (Hegi 1964). In Switzerland, it can mainly be found in south-facing nutrient-poor calcareous meadows and pastures. The plant spreads vegetatively by producing juvenile rosettes at the bases of mature rosettes. Each rosette can produce one or two spike-like 
inflorescences that are composed of up to 70 purple, protandrous zygomorphic flowers (length 10-12 mm, width 3-4 mm) that contain up to $2 \mu \mathrm{l}$ nectar (Hegi 1964; Rusterholz and Erhardt 1998). Flowering occurs from middle of June to the end of August in the northwestern Swiss Jura mountains. The flowers are visited by a variety of generalist pollinators, including bees, bumblebees, hoverflies, butterflies and wasps. Pollinated flowers produce one to four seeds in a nutlet. Up to $20 \%$ of the seeds are fertilized by selfing (H.-P. Rusterholz, unpublished data).

\section{Study sites and experimental design}

The experiment was carried out in three calcareous grasslands in the northwestern Swiss Jura mountains: Nenzlingen $\left(47^{\circ} 28^{\prime} \mathrm{N}, \quad 7^{\circ} 34^{\prime} \mathrm{E}\right.$; elevation $510 \mathrm{~m}$ a.s.l.), Vicques $\left(47^{\circ} 22^{\prime} \mathrm{N}, 7^{\circ} 26^{\prime} \mathrm{E} ; 590 \mathrm{~m}\right.$ a.s.l.) and Movelier $\left(47^{\circ} 25^{\prime} \mathrm{N}\right.$, $7^{\circ} 20^{\prime} \mathrm{E} ; 770 \mathrm{~m}$ a.s.1.). The study sites were located within $20 \mathrm{~km}$ from each other. Originally covered by beech forest, the grasslands have been grazed by cattle for many centuries, leading to the characteristic Mesobromion alliance (Zoller 1954). A study site description can be found in Baur et al. (1996).

The experimental fragmentation of the grasslands was created in April 1993 by mowing the vegetation around the fragments. One experimental unit, hereafter a "block", measured $32 \times 29 \mathrm{~m}$ and contained two small $(0.5 \times$ $0.5 \mathrm{~m})$, one medium $(1.5 \times 1.5 \mathrm{~m})$ and one large fragment $(4.5 \times 4.5 \mathrm{~m})$, each separated by a 5 -m-wide strip of mown vegetation, as well as the mirror-symmetrically arranged control plots of equal size in the undisturbed vegetation of the other half of the block (Fig. 1). Within each block, the positions of the different sizes of fragment-control plot pairs as well as the fragment and control halves were randomised. The blocks were part of larger study areas (1.5-2 ha) that were enclosed by a fence to exclude large herbivores. The experimental fragmentation was maintained from April 1993 to November 1999 by frequently mowing (6-12 times per year) the area between the fragments in the period from March to October. The entire area of the study sites was mown in November every year to prevent succession.

In the present study, we focused on medium and large fragments and the corresponding control plots. Small plots were not considered because they contained too few B. officinalis. Thus, the experimental set-up consisted of 12 blocks with 24 fragments (12 medium and 12 large) and the corresponding 24 control plots distributed over the three study sites. The mean density of $B$. officinalis inflorescences in fragments was 3.8 (individuals $/ \mathrm{m}^{2}$ ) and 3.1 in the control plots. No B. officinalis plants were flowering in the frequently mown isolation zones. In 1993, 1995 and 1999, the performance and seed characteristics of $B$. officinalis

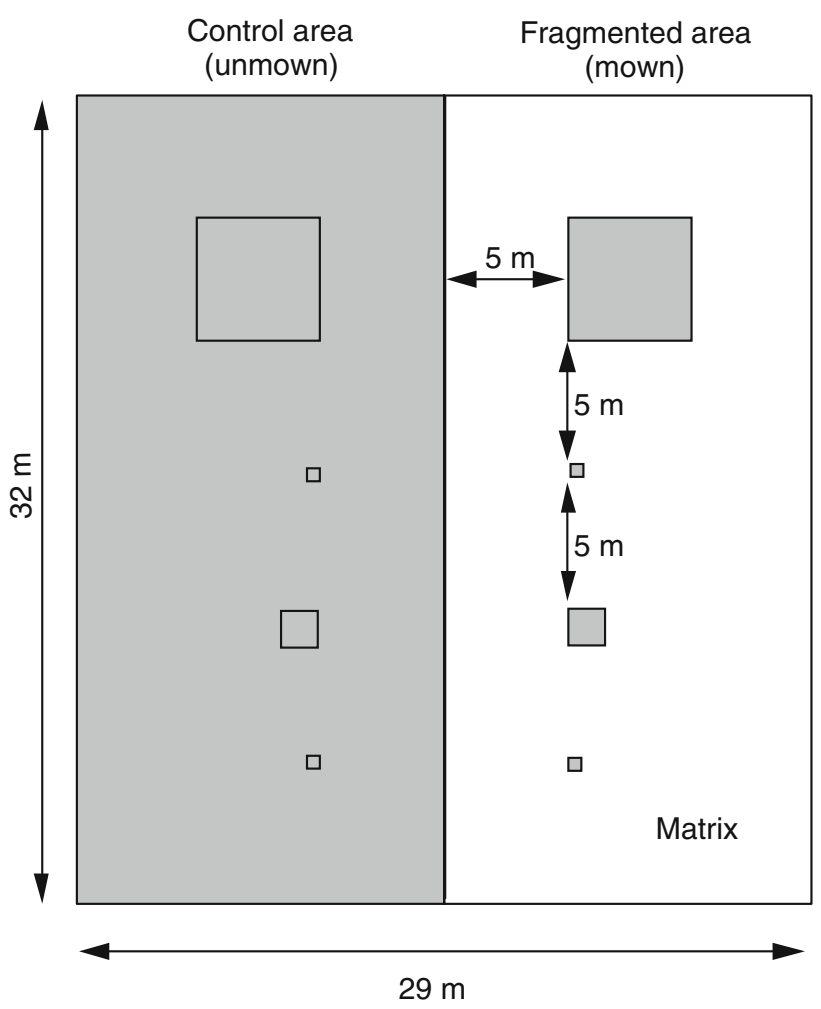

Fig. 1 Layout of one block (out of 12) set up in the field in April 1993. Each block contained four small $\left(0.25 \mathrm{~m}^{2}\right)$, two medium $\left(2.25 \mathrm{~m}^{2}\right)$ and two large plots $\left(20.25 \mathrm{~m}^{2}\right)$. Half of each block served as the control, the other half was experimentally fragmented by frequent mowing between plots. Distance between plots and between plots and continuous vegetation was $5 \mathrm{~m}$. The position of each pair of plots of a given size as well as the position of control and fragmented halves were randomly chosen in each of the 12 blocks. Data from small plots are not considered here

were investigated in all 12 blocks. In 1995 and 1999, flower visitation pattern of $B$. officinalis, foraging behaviour of pollinators and genetic diversity were assessed in a subset of seven blocks situated in Movelier and Vicques.

\section{Plant performance}

We counted the number of rosettes and inflorescences of B. officinalis in each fragment and control plot in the first year of the experiment in July/August 1993 and 2 and 6 years after the initiation of the experimental fragmentation in 1995 and 1999. Total plant height and inflorescence length of each blooming $B$. officinalis were measured during the flowering peak in the same years.

\section{Flower visitation pattern}

Flower visitation rates were assessed in fragments and control plots after 2 and 6 years of experimental fragmentation by counting the number of insects visiting $B$. officinalis inflorescences. During the flowering peak of B. officinalis 
in July/August of 1995 and 1999, each plot was examined for six periods of 20 min on 6 different days, resulting in a total observation time of $2 \mathrm{~h}$ for each plot in both years. The observed flower visitors were assigned to one of six groups (bees, bumblebees, hover flies, butterflies, wasps and others). In bumblebees, which are frequent pollinators of B. officinalis, we assessed the time an individual spent in a plot including the searching time for food plants and the duration of the flower visits. Flower visitors that were already in a plot at the beginning of an observation period were not considered. Furthermore, the duration of bumblebee visits to single $B$. officinalis inflorescences was recorded. Observations were made under weather conditions favourable for insect foraging activity (air temperature $\geq 18^{\circ} \mathrm{C}$, wind speed $\leq 1 \mathrm{~m} / \mathrm{s}$, cloudiness $\leq 25 \%$ ) between 10 a.m. and 4.30 p.m. The order of surveys in fragments and control plots was randomised on each observation day to avoid any bias due to time-dependent differences in pollinator behaviour and activities. To assess the effect of flower abundance on flower visitation rate of $B$. officinalis, the number of plant species in bloom and the total number of open flowers in the plots were recorded on three occasions during the flowering peak of B. officinalis in 1995 and 1999.

\section{Seed set and outcrossing rate}

To examine the effects of experimental grassland fragmentation on seed characteristics of B. officinalis, we collected two to five inflorescences in each medium fragment and control plot and five to 12 inflorescences in each large fragment and control plot in September 1993, 1995 and 1999. To assess the outcrossing rate of $B$. officinalis, leaf samples of rosettes of the mother plants were collected in seven blocks situated in Movelier and Vicques in 1995 and 1999. Leaf samples were stored at $-80^{\circ} \mathrm{C}$ until required for genetic analysis.

We assessed seed set by counting the number of aborted and developed seeds of 20 randomly selected B. officinalis fruits of each inflorescence. Mean seed weight was determined in each inflorescence. Thirty randomly selected seeds from each collected inflorescence were then placed in a pot of $10 \mathrm{~cm}$ diameter filled with a mixture of sand and sieved soil obtained from the study site. Seeds were germinated under controlled environmental conditions $\left(24^{\circ} \mathrm{C}\right.$, $16 \mathrm{~h}$ light $/ 16^{\circ} \mathrm{C}, 8 \mathrm{~h}$ darkness). To estimate the germination rate, the number of newly emerged seedlings was counted every 3 days for 5 weeks. Then three seedlings were randomly chosen in each pot, while the remaining seedlings were cut. The chosen seedlings were allowed to grow for 3 weeks under the conditions described above. For the genetic analysis, one of the three juvenile plants was randomly chosen in each pot.
DNA isolation and RAPD amplification

High-molecular-weight DNA from leaf tissue was isolated following the method of Doyle and Doyle (1987). Template quality and quantity were measured using a spectrophotometer.

To ensure the reproducibility of our RAPD-PCR analysis, 12 randomly chosen leaf and seedling samples from the study sites were screened for decamere primers (Operon Technologies, USA). Out of the 40 primers examined, five primers were selected yielding polymorphic and reproducible bands. DNA was amplified twice with the selected primers to assess reproducibility between runs. The reproducibility of the primers selected ranged from 96.4 to $100 \%$ (Table S1). These five primers were used in the subsequent analyses of the 560 samples collected in 1995 and the 738 samples collected in 1999. One DNA sample served as an additional control to the blanks in every PCR run.

The RAPD-PCR mixture was $25 \mathrm{ng}$ DNA, $0.2 \mu \mathrm{M}$ primer, $200 \mu \mathrm{M}$ of each dNTPs (Pharmacia) and $0.5-1.0$ unit Taq polymerase (Promega) depending on the specific primer. Amplification was achieved in a PCT-100 cycler (MJ Research, USA) under the following conditions: 40 cycles of $1 \mathrm{~min}$ at $94^{\circ} \mathrm{C}, 1 \mathrm{~min}$ at $36^{\circ} \mathrm{C}$, and $2 \mathrm{~min}$ at $72^{\circ} \mathrm{C}$. PCR was finished with an extension of $5 \mathrm{~min}$ at $72^{\circ} \mathrm{C}$.

The amplified products were separated on $1.2 \%$ agarose gels in $0.5 \mathrm{M}$ TRIS-borate-EDTA buffer containing ethidium bromide (concentration: 0.0001\%), using a molecular size standard (Bio-Rad). Each DNA sample was repeated once in separate amplification reactions. DNA from a few leaf samples showed poorly reproducible banding patterns. DNA from these leaves was extracted again and the RAPDPCR procedure was repeated. However, it was impossible to obtain clear RAPD-PCR patterns for a number of leaf samples (46 out of 560 samples in 1995 and 108 out of 738 samples in 1999). Individuals that did not provide clear or reproducible signals were excluded from the analysis.

For data scoring, the banding patterns were recorded using the gel documentation system AlphaImager (Alpha Innotech, CA, USA). The image profile and molecular weight of each band were determined with the fingerprinting software of Bio-Rad (Bio-Rad Laboratories, CA, USA).

\section{Statistical analyses}

We used R statistic (version 2.6.2; R Development Core Team 2008) for all analyses. To avoid pseudoreplication, analyses were performed with the mean values of data gathered in each fragment or control plot. ANOVA and analysis of covariance (ANCOVA) were used because the experiment had a hierarchical split-plot design. If necessary, data were $\log$ or arcsin transformed to obtain normally distributed residuals and homogeneous group variance. 
Effects of fragmentation on density of rosettes and inflorescences of $B$. officinalis $\left(n / \mathrm{m}^{2}\right)$, plant height, inflorescence length and seed set $(\%)$, seed weight and germination rate $(\%)$ were examined using a five-way ANOVA including the factors year, site, block, plot size, fragmentation and their interactions. The block effects were tested against the variation of interaction of fragmentation and block nested within site to eliminate spatial variation within study sites and site effects were tested against the variation between blocks within sites. The effects of fragmentation were tested against the variation of the interaction of block and fragmentation.

Flower visitation rate was defined as the number of insect visits observed in a plot during 20 min divided by the number of $B$. officinalis inflorescences. Spearman rank correlation analysis showed that the number of plant species in bloom (per $\mathrm{m}^{2}$ ) and density of total open flowers of co-flowering plant species were highly correlated: $r_{\mathrm{s}}=0.56, n=56, P=0.001$. Furthermore, the density of all open flowers of co-flowering plant species and the density of $B$. officinalis inflorescences were negatively correlated $\left(r_{\mathrm{s}}=-0.34, n=54, P=0.017\right)$. Therefore, the effects of fragmentation on flower visitation rate were analysed using a five-way ANCOVA considering the five factors listed above and the density of $B$. officinalis inflorescences $\left(n / \mathrm{m}^{2}\right)$ as co-factor.

Regression analysis was performed to examine the relationship between the time bumblebees spent on an inflorescence and the length of the inflorescence (log/log transformed, $\left.R^{2}=0.70, n=54, P<0.0001\right)$. The residuals of this regression analysis were used to evaluate the effects of fragmentation on flower visitation behaviour when applying ANOVA. The same ANOVA model was used to examine the effects of fragmentation on the time bumblebees spent in the plots. Furthermore, contingency analysis was used to test whether the experimental fragmentation changed the species composition of flower visitors in the plots.

Outcrossing frequencies were calculated using the multilocus estimation procedure of Shaw et al. (1981) and van Treuren et al. (1993). This model compares motheroffspring combinations by assigning offspring into one of two classes: discernible outcrosses (progeny exhibit at least one band not present in the maternal phenotype), and ambiguous mating (progeny showing the same banding pattern as the maternal phenotype, and thus may result from self-fertilization). We assumed that outcrossing can be identified by the presence of a band in the offspring (seedling) that was absent in the mother plant (rosette). Outcrossing was only considered to occur if all five primers showed the same result. Outcrossing frequencies were assessed on the plot level by calculating the sum of discernible outcrossing and ambiguous mating events relative to the sample size. We also determined the genetic diversity of the seedlings using Popgene version 1.32 (Yeh et al. 1997). The effects of fragmentation on outcrossing frequency and genetic diversity were examined using the same five-way ANCOVA with the co-factors total flower visitation rate and density of $B$. officinalis inflorescences $\left(n / \mathrm{m}^{2}\right)$. The ANOVA and ANCOVA models were stepwise reduced as recommended by Crawley (2007).

\section{Results}

\section{Plant performance}

Densities of neither B. officinalis rosettes nor inflorescences differed between fragments and control plots or between years (Table 1; Table S2). However, densities of both B. officinalis rosettes and inflorescences were affected by plot size (Table 1). Medium plots (fragments and controls) had higher densities of rosettes and inflorescences than large plots. Total plant height and inflorescence length of B. officinalis did not differ between fragments and control plots (Table 1). However, the plants were taller and the inflorescences bigger after 2 and 6 years of fragmentation than at the beginning of the experiment (Table 1). Inflorescence length of $B$. officinalis was also affected by plot size (Table 1). The inflorescences were larger in both medium fragments and control plots than in the corresponding larger ones. The significant interactions between site and year on inflorescence density, total plant height and inflorescence length of $B$. officinalis indicated a high site-related variation in these plant parameters during the period of investigation.

\section{Flower visitation pattern}

Flower visitation rate was not affected by fragmentation after 2 years $\left(F_{1,6}=1.41, P=0.28\right)$. After 6 years of experimental fragmentation, however, flower visitation rate of $B$. officinalis was significantly reduced in fragments $\left(F_{1,6}=19.51, P<0.001\right)$. Overall, there was a significant fragmentation effect on flower visitation rate (Table 2). Furthermore, there were significant effects of the study sites and plot sizes on the flower visitation rate (Table 2). Comparing the study sites, the overall flower visitation rate was reduced by $19 \%$ at Vicques. Flower visitation rate was reduced by $40 \%$ when medium fragments were compared with medium control plots and by $25 \%$ when large fragments were compared with large control plots (Fig. 2). However, the density of $B$. officinalis inflorescences did not influence the flower visitation rate of $B$. officinalis (Table 2).

Experimental fragmentation caused a shift in the composition of flower visitors (after 2 years, $\chi^{2}=141.29, d f=4$, 
Table 1 Summary of ANOVAs testing the effects of year, site, experimental fragmentation, block and plot size on the densities of rosettes and inflorescences, total plant height and inflorescence length of Betonica officinalis

\begin{tabular}{|c|c|c|c|c|c|c|c|c|c|c|c|c|}
\hline & \multicolumn{3}{|c|}{ Density of rosettes } & \multicolumn{3}{|c|}{ Density of inflorescences } & \multicolumn{3}{|c|}{ Total plant height } & \multicolumn{3}{|c|}{ Inflorescence length } \\
\hline & $d f$ & $F$ & $P$ & $d f$ & $F$ & $P$ & $d f$ & $F$ & $P$ & $d f$ & $F$ & $P$ \\
\hline Year $(Y)$ & 2,105 & 0.18 & 0.834 & 2,105 & 1.09 & 0.162 & 2,92 & 58.02 & $<0.0001$ & 2,92 & 24.63 & $<0.0001$ \\
\hline Site $(S)$ & 2,9 & 0.43 & 0.663 & 2,9 & 0.93 & 0.429 & 2,9 & 2.08 & 0.181 & 2,9 & 0.21 & 0.814 \\
\hline Fragmentation $(F)$ & 1,11 & 0.02 & 0.891 & 1,11 & 0.11 & 0.746 & 1,11 & 0.94 & 0.353 & 1,11 & 0.08 & 0.785 \\
\hline Block(site) $[B(S)]$ & 9,11 & 1.67 & 0.209 & 9,11 & 2.14 & 0.117 & 9,11 & 1.23 & 0.367 & 9,11 & 1.98 & 0.142 \\
\hline Plot size $(P)$ & 1,105 & 13.00 & $<0.0001$ & 1,101 & 6.19 & 0.014 & 1,92 & 0.30 & 0.558 & 1,92 & 12.19 & $<0.0001$ \\
\hline$F \times B(S)$ & 11,105 & 2.33 & 0.013 & 11,101 & 2.13 & 0.025 & 11,92 & 7.07 & $<0.0001$ & 11,92 & 3.57 & $<0.0001$ \\
\hline$F \times P$ & & Excl. & & & Excl. & & & Excl. & & 1,92 & 2.17 & 0.144 \\
\hline$Y \times S$ & & Excl. & & 4,101 & 2.96 & 0.0001 & 4,92 & 15.95 & $<0.0001$ & 4,92 & 6.14 & 0.0001 \\
\hline$Y \times F$ & & Excl. & & & Excl. & & 2,92 & 5.03 & 0.131 & & Excl. & \\
\hline
\end{tabular}

Excl. Excluded from analysis due to the stepwise reduction procedure

Statistical significance indicated by bold letters

Table 2 Summary of analyses of covariance testing the effects of the factors year, site, experimental fragmentation, block and plot size on total flower visitation rate of $B$. officinalis, outcrossing frequency and genetic diversity of seedlings

\begin{tabular}{|c|c|c|c|c|c|c|c|c|c|}
\hline & \multicolumn{3}{|c|}{ Total flower visitation rate } & \multicolumn{3}{|c|}{ Outcrossing frequency } & \multicolumn{3}{|c|}{ Genetic diversity } \\
\hline & $d f$ & $F$ & $P$ & $d f$ & $F$ & $P$ & $d f$ & $F$ & $P$ \\
\hline $\operatorname{Year}(Y)$ & 1,38 & 2.05 & 0.161 & 1,33 & 7.37 & 0.011 & 1,34 & 256.7 & $<0.0001$ \\
\hline Site $(S)$ & 1,5 & 8.23 & 0.035 & 1,5 & 7.75 & 0.039 & 1,5 & 0.78 & 0.418 \\
\hline Fragmentation $(F)$ & 1,6 & 10.69 & 0.017 & 1,6 & 31.14 & 0.001 & 1,6 & 1.89 & 0.218 \\
\hline Block (site) $[B(S)]$ & 5,6 & 0.99 & 0.494 & 5,6 & 0.28 & 0.908 & 5,6 & 0.75 & 0.615 \\
\hline Plot size $(P)$ & 1,37 & 11.58 & 0.002 & 1,33 & 0.21 & 0.644 & 1,34 & 6.06 & 0.019 \\
\hline Total flower visitation rate & & n.a. & & 1,33 & 4.52 & 0.041 & 1,34 & 0.14 & 0.709 \\
\hline Density of $B$. officinalis inflorescences & 1,38 & 1.02 & 0.319 & 1,33 & 0.21 & 0.648 & 1,34 & 1.89 & 0.178 \\
\hline$F \times B(S)$ & 6,38 & 0.17 & 0.980 & 6,33 & 0.80 & 0.573 & 6,34 & 0.49 & 0.811 \\
\hline$F \times P$ & & Excl. & & 1,33 & 0.85 & 0.364 & & Excl. & \\
\hline$Y \times S$ & & Excl. & & & Excl. & & & Excl. & \\
\hline$Y \times F$ & 1,38 & 1.23 & 0.275 & 1,33 & 1.50 & 0.217 & & Excl. & \\
\hline
\end{tabular}

Depending on the test the co-factors were density of $B$. officinalis inflorescences $\left(n / \mathrm{m}^{2}\right)$ or total flower visitation rate. $n . a$. not included in the analysis

Statistical significance indicated by bold letters

$P<0.0001$; after 6 years, $\left.\chi^{2}=55.61, d f=4, P<0.0001\right)$. After 2 years of experimental fragmentation, flowers in medium fragments were more frequently visited by wasps (42.4 vs. $20.0 \%)$ and less frequently visited by bees (18.8 vs. $50.8 \%$ ) than flowers in control plots (Fig. 3). In large fragments, flowers were more frequently visited by hover flies ( 28.9 vs. $8.1 \%$ ) and less frequently visited by bumblebees $(23.1$ vs. $48.0 \%)$ than flowers in the corresponding control plots (Fig. 3). After 6 years of fragmentation, flowers in medium fragments were more frequently visited by wasps (19.6 vs. $4.7 \%)$ and less frequently visited by bees (19.2 vs. $52.5 \%)$ than flowers in control plots (Fig. 3). In large fragments, flowers were more frequently visited by bumblebees ( 35.7 vs. $28.4 \%$ ) and less frequently visited by hover flies (2.4 vs. $6.8 \%$ ) than flowers in the control plots (Fig. 3).

The foraging behaviour of bumblebees (the most abundant pollinator of $B$. officinalis) changed in the course of the fragmentation experiment. Bumblebees did not differ in the time spent in fragments and control plots $(9.7 \pm 0.6 \mathrm{~s}$ vs. $\left.8.9 \pm 0.5 \mathrm{~s} ; F_{1,6}=1.66, P=0.25\right)$ after 2 years of fragmentation. After 6 years, however, foraging bumblebees stayed longer in fragments than in control plots $(21.2 \pm 3.6 \mathrm{~s}$ vs. $\left.12.7 \pm 2.4 \mathrm{~s} ; F_{1,6}=10.1, P=0.019\right)$. The duration of an inflorescence visit did not differ between fragments and control plots after 2 and 6 years of fragmentation $(P>0.37)$. 

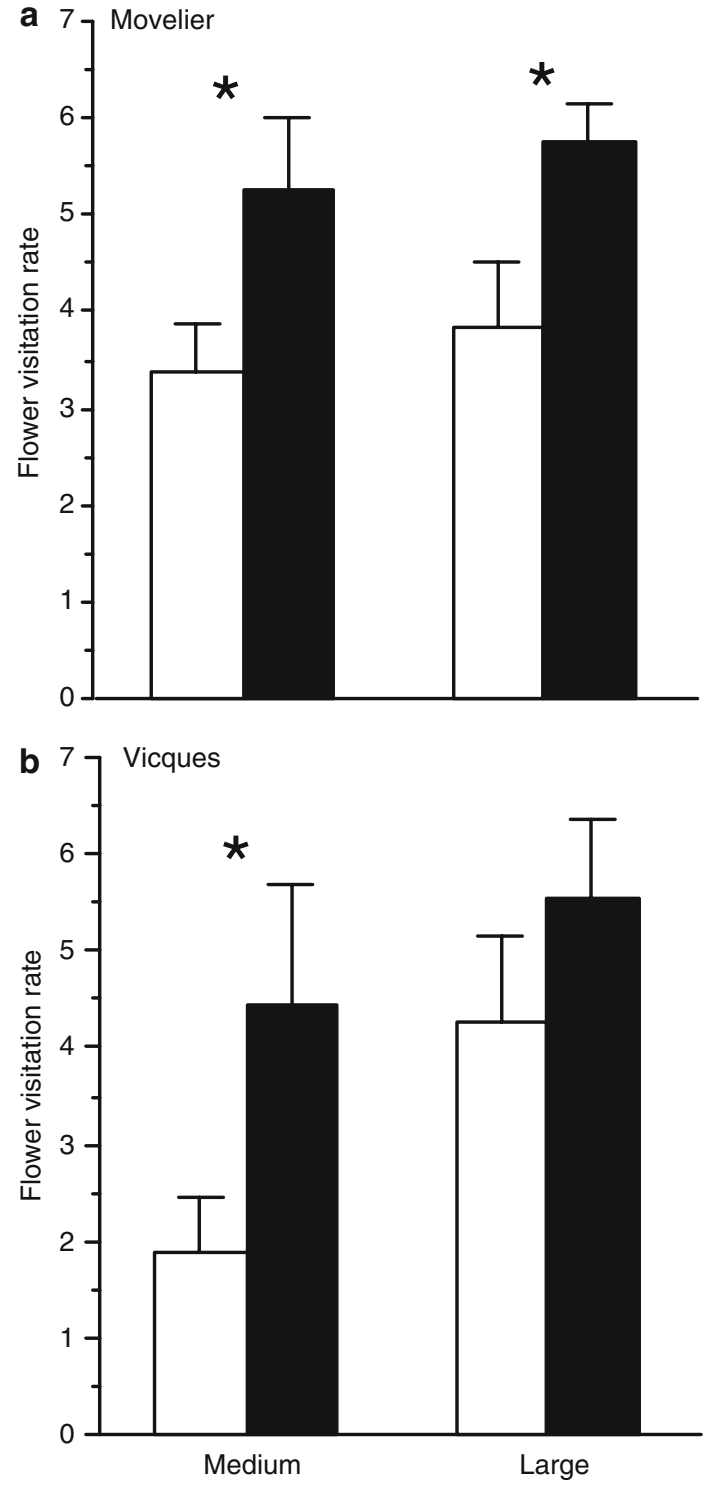

Fig. 2 Flower visitation rate of Betonica officinalis (number of visits per inflorescence during $20 \mathrm{~min}$ ) in medium and large fragments (open bars) and the corresponding control plots (black bars) at the study sites in $\mathbf{a}$ Movelier and $\mathbf{b}$ Vicques [means $\pm \mathrm{SE}$ (error bars) are shown; $n=14] . * P<0.05$ (Wilcoxon rank sum test)

Seed set, seed weight and germination rate

Seed set, seed weight and germination rate of B. officinalis were not influenced by the experimental fragmentation (Table 3; Table S3). Seed set and seed weight differed among years. Both traits were larger after 6 years of fragmentation than at the beginning of the experiment and after 2 years of fragmentation. The significant interactions between year and site indicated that seed set and seed
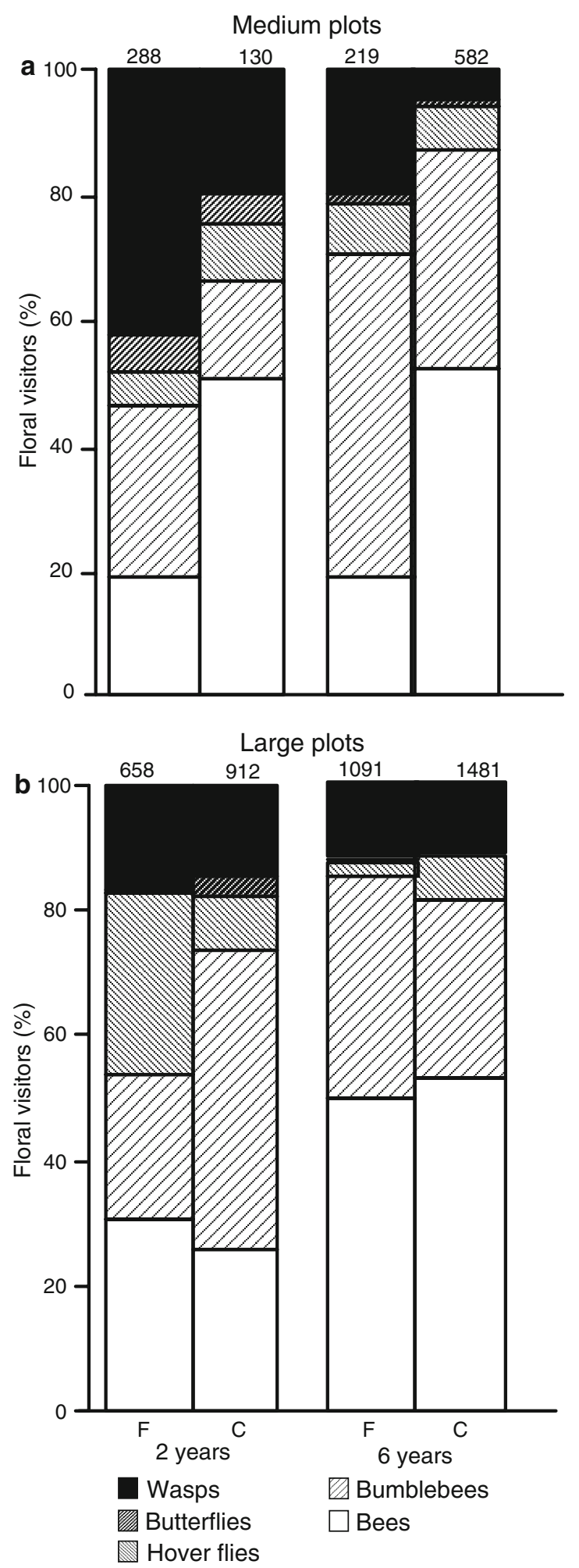

Fig. 3 Frequency of flower visitors of B. officinalis in a medium and b large fragments $(F)$ and the corresponding control $(C)$ plots after 2 and 6 years of experimental fragmentation. Values above bars indicate the number of flower visitors recorded in the plots 
Table 3 Summary of ANOVAs testing the effects of year, site, experimental fragmentation, block and plot size on seed set, seed weight and germination rate of $B$. officinalis

\begin{tabular}{|c|c|c|c|c|c|c|c|c|c|}
\hline & \multicolumn{3}{|c|}{ Seed set $(\%)$} & \multicolumn{3}{|c|}{ Seed weight (mg) } & \multicolumn{3}{|c|}{ Germination rate $(\%)$} \\
\hline & $d f$ & $F$ & $P$ & $d f$ & $F$ & $P$ & $d f$ & $F$ & $P$ \\
\hline $\operatorname{Year}(Y)$ & 2,92 & 56.19 & $<0.0001$ & 1,91 & 28.96 & $<0.0001$ & 2,98 & 0.39 & 0.678 \\
\hline Site $(S)$ & 2,9 & 9.82 & 0.0001 & 2,9 & 6.41 & 0.002 & 2,9 & 3.70 & 0.067 \\
\hline Fragmentation $(F)$ & 1,11 & 1.89 & 0.196 & 1,11 & 0.02 & 0.890 & 1,11 & 1.54 & 0.240 \\
\hline Block(site) $[B(S)]$ & 9,11 & 0.68 & 0.714 & 9,11 & 1.61 & 0.225 & 9,11 & 1.16 & 0.401 \\
\hline Plot size $(P)$ & 1,92 & 2.58 & 0.111 & 1,91 & 0.77 & 0.380 & 1,98 & 4.39 & 0.039 \\
\hline$F \times B(S)$ & 11,92 & 4.21 & $<0.0001$ & 11,91 & 2.31 & 0.015 & 11,98 & 2.84 & 0.002 \\
\hline$F \times P$ & 1,92 & 10.79 & 0.001 & 1,91 & 1.69 & 0.196 & & Excl. & \\
\hline$Y \times S$ & 4,92 & 15.40 & $<0.0001$ & 4,91 & 10.68 & $<0.0001$ & & Excl. & \\
\hline$Y \times F$ & & Excl. & & 2,91 & 8.35 & 0.0005 & & Excl. & \\
\hline
\end{tabular}

Statistical significance indicated by bold letters

weight varied differently at the study sites and in different years (Table 3). Germination rate was not affected by fragmentation, but was higher in large plots (fragments and controls) than in medium plots (Table 3 ).

Outcrossing frequency and genetic diversity

The outcrossing frequency of $B$. officinalis was reduced by fragmentation and decreased with duration of the experiment (Table 2; Fig. 4). After 2 years, the frequency of outcrossing was $78.8 \%$ in fragments and $93.8 \%$ in control plots $\left(F_{1,6}=7.73, P=0.032\right)$ and after 6 years, the frequency of outcrossing averaged $59.5 \%$ in fragments and $95.6 \%$ in control plots $\left(F_{1,6}=27.93, P<0.0001\right)$. The outcrossing frequency also differed between the study sites. Compared to the control plots, the outcrossing frequency was reduced by $42 \%$ in fragments in Movelier and by $27 \%$ in Vicques. The outcrossing frequency was not influenced by plot size (Table 2). The flower visitation rate had a significant effect on the outcrossing frequency of $B$. officinalis (Table 2). In contrast, the density of B. officinalis inflorescences did not influence the outcrossing frequency (Table 2).

Overall, the genetic diversity of the $B$. officinalis seedlings did not differ between fragments and control plots (Table 2). However, when different years are analysed separately, genetic diversity of seedlings was significantly lower in fragments than in control plots $(0.210 \pm 0.029$ vs. $\left.0.271 \pm 0.026 ; F_{1,6}=12.05, P=0.014\right)$ after 6 years of fragmentation. After 2 years, the genetic diversity of seedlings did not differ between fragments and control plots $\left(F_{1,6}=3.39, P=0.12\right)$. The genetic diversity increased by $38 \%$ from 2 to 6 years of experimental fragmentation. The flower visitation rate and density of $B$. officinalis inflorescences did not influence the genetic diversity of seedlings (Table 2).

\section{Discussion}

Habitat fragmentation is expected to change the behaviour, frequency and composition of flower visitors which in turn might affect pollination efficiency determining the quantity and/or quality of pollen deposited on the stigmas and therefore seed and fruit production (Aguilar and Galetto 2004). Natural microcosms have been acknowledged as suitable tools for testing effects of habitat fragmentation, metacommunity theory and links between biodiversity and ecosystem processes (Shrivastava et al. 2004). Our study showed that experimental grassland fragmentation altered the composition of $B$. officinalis pollinators and reduced the flower visitation rate. Furthermore, the foraging behaviour of bumblebees, one of the most frequent pollinators of B. officinalis, was changed. As a consequence, the outcrossing rate of $B$. officinalis decreased in the fragments. In contrast, the experimental fragmentation only marginally affected the performance of $B$. officinalis.

The shift in pollinator composition and reduced flower visitation rate of $B$. officinalis in fragments recorded in this study are in line with the findings of several other studies (Jennersten 1988; Smith-Ramirez and Armesto 2003), although these studies were conducted on a much larger spatial scale. Some studies also provide evidence that the patchiness, size and density of floral resources are more important than habitat fragmentation in determining the flower visitation behaviour of pollinators (Jennersten and Nilsson 1993; Klinkhamer et al. 2001; Ishii et al. 2008). In our study, however, ANCOVA analyses revealed that neither the density of $B$. officinalis inflorescences nor the total density of open flowers of co-flowering plant species in the plots affected the flower visitation rate. This indicates that the reduced flower visitation rate in fragments was not caused by differences in floral resources between fragments and control plots. It is also possible that differences in the 

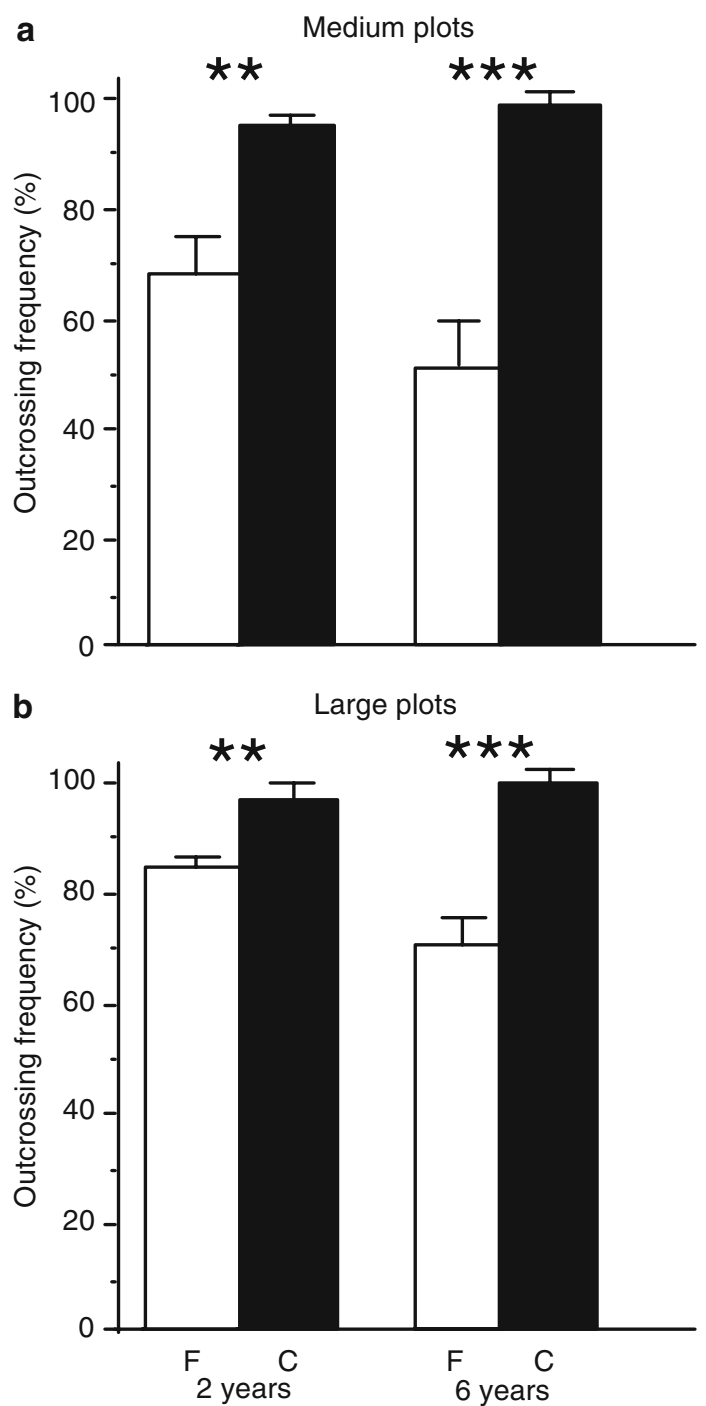

Fig. 4 Frequency of outcrossing in B. officinalis in a medium and b large $\mathrm{F}$ and $\mathrm{C}$ plots after 2 and 6 years of experimental fragmentation [means $\pm \mathrm{SE}$ (error bars) are shown; $n=7$ ]. For abbreviations, see Fig. 3. $* * P<0.01, * * * P<0.001$ (Wilcoxon rank sum test)

total abundance of floral resources between the control part and the treatment part of a block could influence the flower visitation rate. However, in the present study the flower resources showed very similar spatial distribution patterns and abundances in the control parts and the treatment parts (fragments).

The experimental habitat fragmentation also altered the foraging behaviour of bumblebees. Bumblebees were the most frequent pollinators of $B$. officinalis, responsible for more than $50 \%$ of all flower visits. Two years after the initiation of the experiment, we frequently observed bumblebees foraging in the matrix and rarely entering the fragments. After 6 years of fragmentation, however, bumblebees showed a preference to forage in fragments. The change in the foraging behaviour of bumblebees is con- firmed by other studies demonstrating a remarkable patch constancy besides their ability to fly long distances (Cresswell 2000). Bumblebees visit repeatedly the same patches of floral resources (Osborne and Williams 2001) and frequently use specific plant-to-plant foraging routes (Thomson et al. 1987). However, the foraging behaviour of bumblebees is plastic and can easily be adjusted to changes in the environment (Chittka and Thomson 1997). Because long-distance flying is expensive in terms of energy, the bumblebees may optimize their net energy gain by adjusting their foraging behaviour to the changing spatial distribution of floral resources induced by the experimental fragmentation (Zimmerman 1982).

A reduced flower visitation rate of pollinators in fragments may decrease gene flow among plants and thus affect their breeding system (Grindeland 2008). In the present study, seed set of B. officinalis was only marginally affected by experimental fragmentation and seed weight was even higher in fragments than in control plots after 6 years of fragmentation. Thus no negative effects of inbreeding indicated by reductions in seed set, seed weight and/or germination rate were found in $B$. officinalis. This is not surprising because self-pollination usually accounts for up to $20 \%$ of B. officinalis' seed set in the wild (H.-P. Rusterholz, unpublished data). Our results are in line with the findings in various other plant species showing that neither seed set, seed weight nor germination rate were affected by habitat fragmentation (Costin et al. 2001; Aquirre and Dirzo 2008). Furthermore, our results confirmed the assumption that habitat fragmentation affects self-compatible plants with different pollinators less than self-incompatible plants with a single specialized pollinator (Waser et al. 1996; Aizen et al. 2002).

In self-compatible plants, the level of outcrossing is influenced by the number of outcrossing pollen deposited on the stigmas (Lloyd 1980). We found a reduced outcrossing frequency in B. officinalis growing in fragments. After 2 years of fragmentation, the outcrossing frequency decreased to $73 \%$ in fragments, and after 6 years to $60 \%$, whereas in control plots the outcrossing frequency ranged from 94 to $97 \%$.

Different types of genetic markers have been used to determine outcrossing rates in plant species (Lowe et al. 2004). Consequently, only studies using the same type of markers and the same resolution can be compared (Aguilar et al. 2008). The frequency of outcrossing found in our study is similar to the outcrossing rates of Scabiosa columbaria (van Treuren et al. 1994) and Salvia pratensis (van Treuren et al. 1993). The among-individual variation in outcrossing frequency in B. officinalis (0-83\% in fragments and 78 $100 \%$ in control plots) was larger than those reported for other self-compatible plant species including Eucalyptus benthamii (Butcher et al. 2005) or Aquilegia canadensis 
(Routley et al. 1999). Apart from pollinator abundance, interfloral flight distance, body size and foraging pattern of the pollinators may also influence the plant mating system (Karron et al. 1995). In the present study, neither the number of flower visits nor flower offer affected the outcrossing frequency of $B$. officinalis. The reduced outcrossing frequency was most probably a result of the combined effects of an altered pollinator composition, a changed foraging behaviour of the pollinators and a reduced flower visitation rate. The reduced outcrossing frequency in the fragments could also be due to a higher rate of geitonogamy, because bumblebees spent more time in fragments than in the control plots. Low outcrossing rates reduce the genetic diversity of the remnant populations in subsequent generations. Within each population, the risk of losing alleles through genetic drift will increase with the level of inbreeding, leading to possible reductions in plant fitness and eventual extinctions (Fischer and Matthies 1997). The reduced genetic diversity in $B$. officinalis seedlings was not found until the sixth year of experimental fragmentation. This suggests that perennial plants like $B$. officinalis may show less genetic erosion due to genetic drift and enhanced inbreeding than annual or biennial plant species (Young et al. 1996).

In the present study, the plant-pollinator system showed a delayed response to experimental fragmentation. This delay could be a result of both year-to-year variation in the abundance and composition of pollinators and different weather conditions in the years of our investigation (Herrera 1995). In our study, observations of pollinators were only made under climatic conditions favourable for insect activity, thus reducing any bias due to different weather conditions. However, we found differences in the abundance and composition of pollinators among years (Fig. 3). The differences in pollinator guilds were mainly a result of variation in bee and bumblebee abundance. B. officinalis and other plant species pollinated by generalist insects might be less affected by among-year differences in the abundance and composition of pollinators than plants depending on specialized pollinators, because the absence of a given pollinator can be buffered by the presence of others (Morris 2003). Furthermore, different insects could differ in their efficiency to pollinate B. officinalis flowers. In the present study, however, the five pollinator guilds did not differ in their load of B. officinalis pollen (H.-P. Rusterholz, unpublished data) indicating that this factor may play a minor role in this plant-pollinator system. Repeated mowing of the isolation zones ( 6 times per year) changed the species composition and vegetation structure of the matrix (Fig. S4). The altered foraging behaviour of pollinators may therefore be the result of changes in the composition and structure of the vegetation growing in the matrix after 6 years of experimental fragmentation (Zschokke et al. 2000; Fig. S4). The finding that the quality of the matrix can be a key factor determining the response of plants and animals to habitat fragmentation was confirmed by other studies (Hirsch et al. 2003; Williams et al. 2006).

The present study showed that several plant breeding parameters were not affected by fragmentation-related changes in the reproductive system of $B$. officinalis. Furthermore, our study showed that long-term field experiments are necessary to disentangle slight changes in plantpollinator interactions and to estimate the resulting effects on the outcrossing frequency and genetic diversity in plant populations.

Acknowledgments We thank numerous students for field assistance, Anette Baur and three anonymous reviewers for valuable comments on the manuscript. Financial support was received from the Swiss National Science Foundation (grant to B. B.). The reported experiment complies with the current laws of Switzerland.

\section{References}

Ågren J (1996) Population size, pollinator limitation and seed set in the self-compatible herb Lythrum salicaria. Ecology 77:1779-1790

Aguilar R, Galetto L (2004) Effects of forest fragmentation on male and female reproductive success in Cestrum parqui (Solanaceae). Oecologia 138:213-220

Aguilar R, Ashworth L, Galetto L, Aizen MA (2006) Plant reproductive susceptibility to habitat fragmentation: review and synthesis through meta-analysis. Ecol Lett 9:968-980

Aguilar R, Quesada M, Ashworth L, Herrerias-Diego Y, Lobo J (2008) Genetic consequences of habitat fragmentation in plant populations: susceptible signals in plant traits and methodological approaches. Mol Ecol 17:5177-5188

Aizen MA, Feinsinger P (1994) Forest fragmentation, pollination, and plant reproduction in a Chaco dry forest, Argentina. Ecology 75:330-351

Aizen MA, Ashworth L, Galetto L (2002) Reproductive success in fragmented habitats: do compatibility system and pollination specialization matter? J Veg Sci 13:885-892

Aquirre A, Dirzo R (2008) Effects of fragmentation on pollinator abundance and fruit set of an abundant understory palm in a Mexican tropical forest. Biol Conserv 141:375-384

Baur B, Joshi J, Schmid B, Hänggi A, Borcard D, Stary J, PedroliChristen A, Thommen GH, Luka H, Rusterholz HP, Oggier P, Ledergerber S, Erhardt A (1996) Variation in species richness of plants and diverse groups of invertebrates in three calcareous grasslands of the Swiss Jura mountains. Rev Suisse Zool 103:801-833

Bond WJ (1994) Do mutualisms matter? Assessing the impact of pollinator and disperser disruption on plant populations. Philos Trans R Soc Lond B 344:83-90

Buchmann SL, Nabhan GP (1996) The forgotten pollinators. Island Press, Washington, DC

Butcher PA, Skinner AK, Gardiner GA (2005) Increased inbreeding and inter-species gene flow in remnant populations of the rare Eucalyptus benthamii. Conserv Genet 6:213-226

Chittka L, Thomson JD (1997) Sensori-motor learning and its relevance for task specialization in bumble bees. Behav Ecol Sociobiol 41:385-398

Costin BJ, Morgan JW, Young AG (2001) Reproductive success does not decline in fragmented populations of Leucochrysum albicans 
subsp. albicans var. tricolor (Asteracea). Biol Conserv 98:273284

Crawley MJ (2007) The R book. Wiley, Chichester

Cresswell JE (2000) A comparison of bumblebees' movements in uniform and aggregated distribution of their forage plant. Ecol Entomol 25:19-25

Development Core Team R (2008) R: a language and environment for statistical computing. R Foundation for Statistical Computing, Vienna

Doyle JJ, Doyle JL (1987) A rapid DNA isolation procedure for small quantities of fresh leaf tissue. Phytochem Bull 19:11-15

Duncan DH, Nicotra AB, Wood JT, Cunninghman SA (2004) Plant isolation reduces outcross pollen receipt in a partially selfcompatible herb. J Ecol 92:977-985

Ewers RM, Didham RK (2006) Confounding factors in the detection of species responses to habitat fragmentation. Biol Rev 81:117-142

Fischer M, Matthies D (1997) Mating structure and inbreeding and outbreeding depression in the rare plant Gentianella germanica (Gentianacea). Am J Bot 84:1685-1692

Ghazoul J (2005) Pollen and seed dispersal among dispersed plants. Biol Rev 80:413-444

Gilpin ME, Soulé ME (1986) Minimum viable populations: processes in species extinction. In: Soulé ME (ed) Conservation biology: the science of scarcity and diversity. Sinauer, Sunderland, pp 19-34

Goverde M, Schweizer K, Baur B, Erhardt A (2002) Small-scale fragmentation affects pollinator behaviour: experimental evidence from the bumblebee Bombus veteranus on calcareous grasslands. Biol Conserv 104:293-299

Grindeland JM (2008) Inbreeding depression and outbreeding depression in Digitalis purpurea: optimal outcrossing distance in a tetraploid. J Evol Biol 21:716-726

Groppe K, Steinger T, Schmid B, Baur B, Boller T (2001) Effects of habitat fragmentation on choke disease (Epichloë bromicola) in the grass Bromus erectus. J Ecol 89:247-255

Hegi G (1964) Illustrierte Flora von Mitteleuropa. Hanser, Munich

Helm A, Hanski I, Pärtel M (2006) Slow response of plant species richness to habitat loss and fragmentation. Ecol Lett 9:72-77

Herrera CM (1995) Microclimate and individuals variation in pollinators: flowering plants are more than their flowers. Ecology 76:1516-1524

Hirsch M, Pfaff S, Wolters V (2003) The influence of matrix type on flower visitors of Centaurea jacea L. Agric Ecosyst Environ 98:331-337

Holsinger KE (2000) Demography and extinction in small populations. In: Young AG, Clarke GM (eds) Genetics demography and viability of fragmented populations. Cambridge University Press, Cambridge, pp 55-74

Ishii HS, Hirabayashi Y, Kudo G (2008) Combined effects of inflorescence architecture, display size, plant density and empty flowers on bumble bee behavior: experimental study with artificial inflorescences. Oecologia 156:341-350

Jennersten O (1988) Pollination in Dianthus deltoides (Caryophyllaceae): effects of habitat fragmentation on visitation and seed set. Conserv Biol 2:359-366

Jennersten O, Nilsson SG (1993) Insect flower visitation frequency and seed production in relation to patch size of Viscaria vulgaris (Caryophyllaceae). Oikos 68:283-292

Karron JD, Thumser NN, Tucker R, Hessenauer AJ (1995) The influence of population density on outcrossing rates in Mimulus ringens. Heredity 75:175-180

Kearns CA, Inouye DW, Waser NM (1998) Endangered mutualisms: the conservation of plant-pollinator interactions. Annu Rev Ecol Syst 29:83-112

Klein AM, Vaissières BE, Cane JH, Steffan-Dewenter I, Cunninghman SA, Kremen C, Tscharntke T (2007) Importance of pollinators in changing landscape for world crops. Proc R Soc B 274:303-313
Klinkhamer PGL, de Jong TJ, Linnebank LA (2001) Small-scale spatial patterns determine ecological relationships: an experimental example using nectar production rates. Ecol Lett 4:559-567

Krauss J, Klein AM, Steffan-Dewenter L, Tscharntke I (2004) Effects of habitat area, isolation and landscape diversity on plant species richness of calcareous grasslands. Biodiv Conserv 13:1427-1439

Lienert J (2004) Habitat fragmentation effects on fitness of plant populations: a review. J Nat Conserv 12:53-72

Lloyd DG (1980) Sexual strategies in plants. III. A quantitative method for describing the gender of plants. N Z J Bot 18:103-108

Lowe A, Harris H, Ashton P (2004) Ecological genetics, design, analysis and applications. Blackwell, Oxford

Morris WF (2003) Which mutualists are most essential? Buffering of plant reproduction against extinction of pollinators. In: Kareiva P, Levin S (eds) The importance of species: perspectives on expendability and triage. Princeton University Press, Princeton, pp 260-280

Murcia C (1996) Forest fragmentation and the pollination of Neotropical plants. In: Schelhas J, Greensberg R (eds) Forest patches in tropical landscape. Island Press, Washington, DC, pp 19-36

Osborne JL, Williams IH (2001) Site constancy of bumble bee in an experimentally patch habitat. Agric Ecosyst Environ 83:129-141

Pacha MJ, Petit S (2008) The effect of landscape structure and habitat quality on the occurrence of Geranium sylvaticum in fragmented hay meadows. Agric Ecosyst Environ 123:81-87

Routley MB, Mavraganis K, Eckert CG (1999) Effect of population size on the mating system in a self-compatible, autogamous plant, Aquilegia canadensis (Ranunculacea). Heredity 82:518-528

Rusterholz H-P, Erhardt A (1998) Effects of elevated $\mathrm{CO}_{2}$ on flowering phenology and nectar production in important nectar plants for butterflies of calcareous grasslands. Oecologia 113:341-349

Saunders DA, Hobbs RJ, Margules CR (1991) Biological consequences of ecosystem fragmentation: review. Conserv Biol 5:18 32

Shaw DVL, Kahler AL, Allard RW (1981) A multilocus estimator of mating system parameters in plant populations. Proc Natl Acad Sci USA 78:1298-1302

Shrivastava DS, Kolasa J, Bengtsson J, Gonzalez A, Lawler SP, Miller TE, Mungia P, Romanuk T, Schneider DC, Trinzcinski MK (2004) Are natural microcosms useful model systems for ecology? Trends Ecol Evol 19:379-384

Smith-Ramirez C, Armesto JJ (2003) Foraging behaviour of bird pollinators on Embothrium coccineum (Protaceae) trees in forest fragments and pastures in southern Chile. Aust Ecol 28:53-60

Thomson JD, Peterson SC, Harder LD (1987) Response of trap lining bumble bees to competition experiments-shifts in feeding location and efficiency. Oecologia 71:295-300

van Treuren R, Bijlsma R, Ouborg NJ, van Delden W (1993) The effects of population size and plant density on outcrossing rates in locally endangered Saliva pratensis. Evolution 47:1094-1104

van Treuren R, Bijlsma R, Ouborg NJ, Kwak MM (1994) Relationships between plant density, outcrossing rates and seed set in natural and experimental populations of Scabiosa columbaria. J Evol Biol 7:287-302

Waites AR, Ågren J (2004) Pollinator visitation, stigmatic pollen loads and among-population variation in seed set in Lythrum salicaria. J Ecol 92:512-526

Ward M, Johnson SD (2005) Pollen limitation and demographic structure in small fragmented populations of Brunsvigia radulosa (Amaryllidaceae). Oikos 108:253-262

Waser NM, Chittka L, Price MV, Williams NM, Ollerton J (1996) Generalization in pollination systems, and why it matters. Ecology $77: 1043-1060$

Williams NSG, Morgan JW, McCarthy MA, McDonnel MJ (2006) Local extinction of grassland plants: The landscape matrix is more important than patch attributes. Ecology 87:3000-3006 
Yeh F, Yang R, Boyle T (1997) Popgene version 1.31. Microsoft Windows-based freeware for population genetic analysis

Young AG, Boyle T, Brown T (1996) The population genetic consequences of habitat fragmentation for plants. Trends Ecol Evol 11:413-418

Zimmerman M (1982) Optimal foraging, plant density and the marginal value theorem. Oecologia 49:148-153
Zoller H (1954) Die Typen der Bromus erectus-Trockenwiesen des Schweizer Juras. Huber, Bern

Zschokke S, Dolt C, Rusterholz HP, Oggier P, Braschler B, Thommen GH, Lüdin E, Erhardt A, Baur B (2000) Short-term responses of plants and invertebrates to experimental small-scale grassland fragmentation. Oecologia 125:559-572 